Thorax (1974), 29, 475.

\title{
Primary mediastinal tumours
}

\author{
Y O US I F D. A L - N A A M A , M OH A M A D S. A L - A N I, \\ a n d M U A Y Y A D . A L - O M E R I
}

Department of Thoracic and Cardiovascular Surgery, College of Medicine, University of Baghdad, Baghdad, Iraq

\begin{abstract}
Al-Naaman, Y. D., Al-Ani, M. S., and Al-Omeri, M. M. (1974). Thorax, 29, 475-481. Primary mediastinal tumours. A review of 28 patients with primary mediastinal tumours seen over a five-year period is presented. Clinical and pathological features of a heterogeneous group of tumours are emphasized. Since a number of patients presented with mild symptoms or were asymptomatic (especially adults), the importance of routine chest radiographs is stressed. Complete excision was accomplished in all patients with benign lesions. Malignant lesions were usually partially resectable and carried a poor prognosis.
\end{abstract}

A majority of mediastinal tumours behave as space-occupying lesions and are a potential threat from pressure on adjacent organs, particularly the superior vena cava and the trachea, with the manifestation of acute respiratory distress requiring emergency decompression (Al-Naaman, Samarrai, Al-Khaddar, and Hasso, 1972). A large variety of primary and secondary tumours and cysts may be found in the ill-defined group of mediastinal spaces. The increasing accessibility of mediastinal structures to the surgeon, as the result of improving surgical techniques, has stimulated interest in neoplasms of this region. In consequence of this and the improved methods of diagnosis, more of these neoplasms have recently been reported by Boyd and Midell (1968), Wychulis, Payne, Clagett, and Woolner (1971), Benjamin, McCormack, Effler, and Groves (1972), La Franchi and Fonkalsrud (1973), and Hallgrimsson (1972).

The purpose of this study is to review some mediastinal tumours that required surgical exploration in our department for tissue diagnosis as well as for treatment and to provide data regarding the current status of these lesions. Cardiovascular, tracheal, oesophageal, and pulmonary lesions and hydatid cysts are excluded from the present study.

\section{MATERIAL}

Twenty-eight tissue-documented primary mediastinal tumours were encountered at The Medical City Teaching Hospital, Baghdad over a five-year period. The study included all patients operated on during that period. All case histories, gross pathological reports, and histopathological sections were reviewed. The ages of the patients in this series ranged between 2 and 69 years. There were no significant differences in sex distribution. The group was subdivided into histopathological categories in decreasing order of frequency (Table).

T A B L E

PATHOLOGICAL CLASSIFICATION OF 28 TUMOURS OF THE MEDIASTINUM

\begin{tabular}{|c|c|}
\hline Pathological Findings & No. of Cases \\
\hline $\begin{array}{l}\text { Lymphoreticular } \\
\text { Lymphoma } \\
\text { Lymphosarcoma } \\
\text { Reticulum-cell sarcoma } \\
\text { Hodgkin's disease } \\
\text { Thymoma }\end{array}$ & $\begin{array}{l}3 \\
1 \\
1 \\
1 \\
2\end{array}$ \\
\hline $\begin{array}{l}\text { Neurogenic } \\
\text { Neurofibroma }\end{array}$ & 6 \\
\hline $\begin{array}{l}\text { Displaced thyroid } \\
\text { Papillary adenocarcinoma } \\
\text { Retrosternal goitre }\end{array}$ & $\begin{array}{l}1 \\
4\end{array}$ \\
\hline $\begin{array}{l}\text { Mesenchymal } \\
\text { Fibrosarcoma } \\
\text { Lipoma } \\
\text { Poorly differentiated sarcoma } \\
\text { Osteoma } \\
\text { Chondrosarcoma }\end{array}$ & $\begin{array}{l}1 \\
1 \\
1 \\
1 \\
1\end{array}$ \\
\hline $\begin{array}{l}\text { Teratodermoidal } \\
\text { Malignant teratoma } \\
\text { Dermoid }\end{array}$ & 1 \\
\hline \multirow[t]{2}{*}{ Granulomatous (TB) } & 2 \\
\hline & 28 \\
\hline
\end{tabular}

DISCUSSION AND CONCLUSIONS

The most common lesions encountered in the mediastinum in our series were lymphoreticular lesions (lymphoma and thymoma) (Figs 1 to 3 ). 


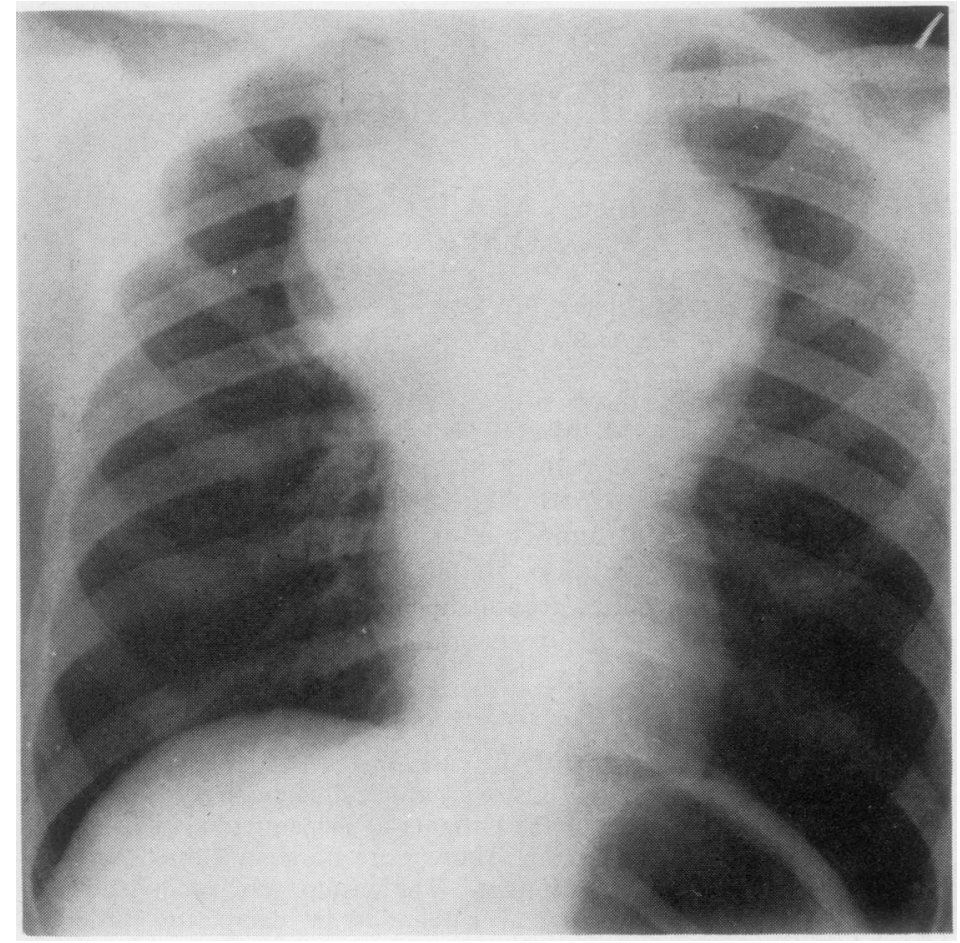

FIG. 1. Lymphoma in 17-year-old male with dyspnoea, cough, and puffiness of the face of one month's duration.

FIG. 2. A 2-year-old child with fever, cough, and severe dyspnoea of 40 days' duration. Thoracotomy was necessary to establish the presence of a reticulum-cell sarcoma and to relieve the compression. The child was sent back to the paediatric service two weeks after surgery and treated with cytotoxic drugs and radiotherapy.

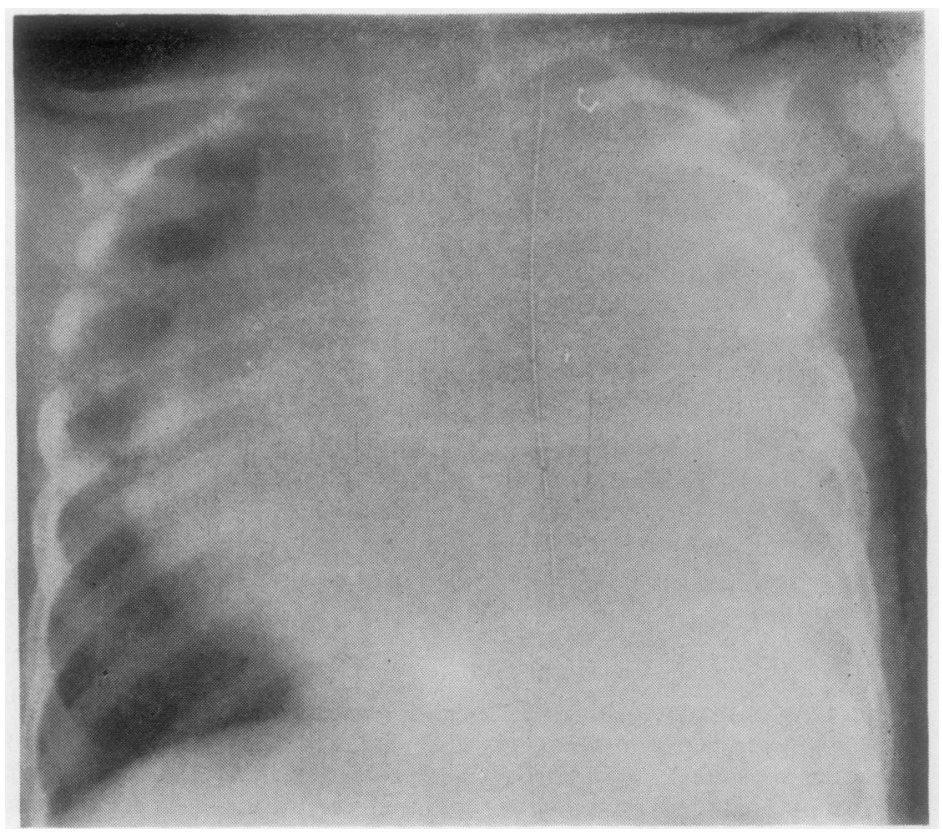




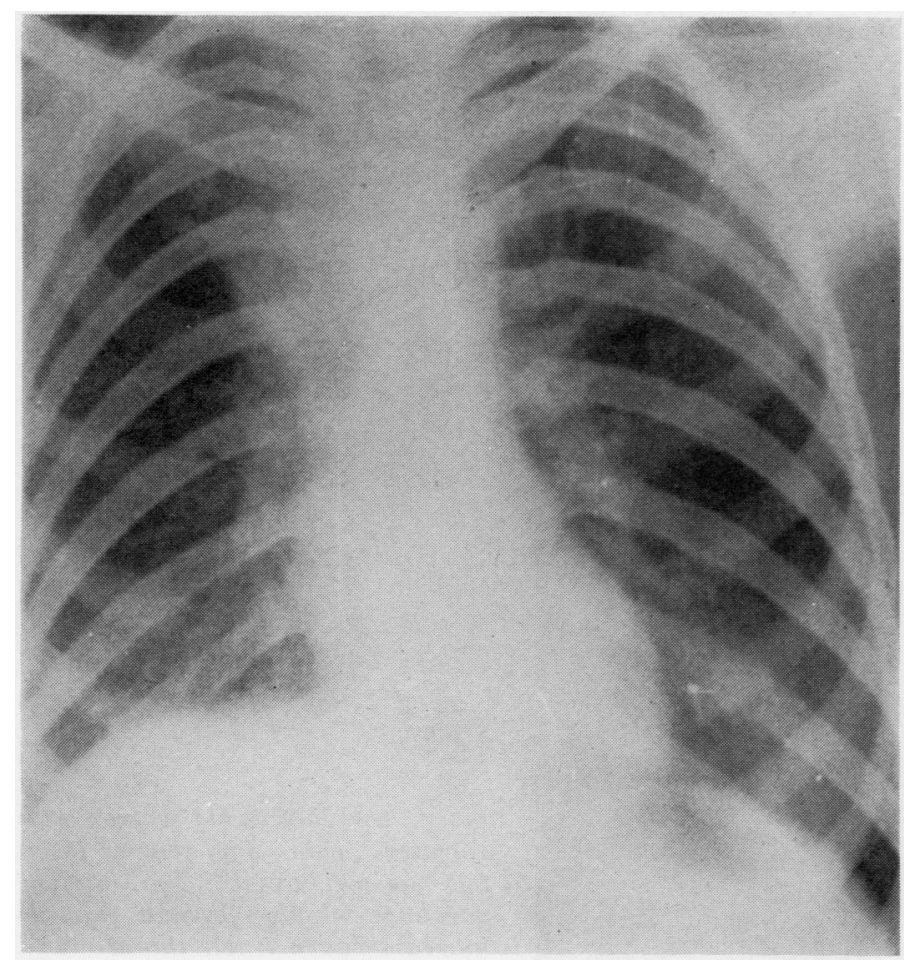

FIG. 3. Recurrent malignant thymoma in a 27-year-old woman resected seven years previously as an emergency because of severe respiratory distress. Irradiation given postoperatively. Well for seven years.

FIG. 4. Retrosternal goitre in 65-yearold man with progressive dyspnoea and signs of compression on the trachea and superior vena cava. The tumour was removed through a median sternotomy.

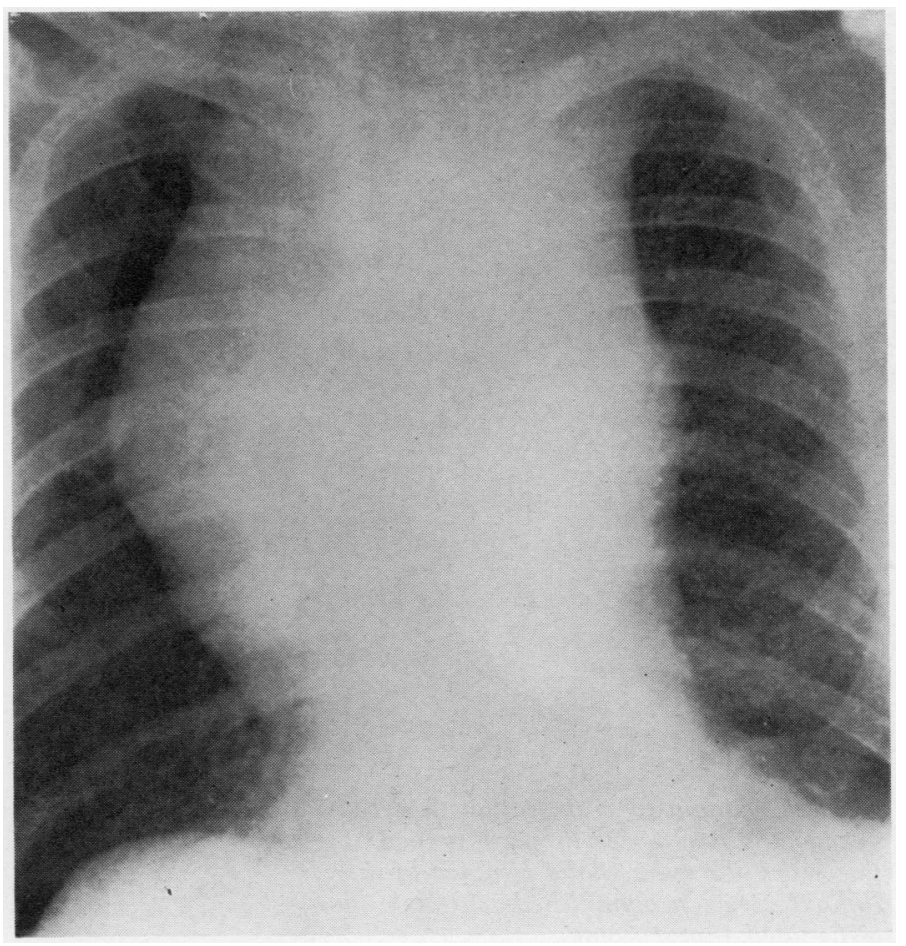




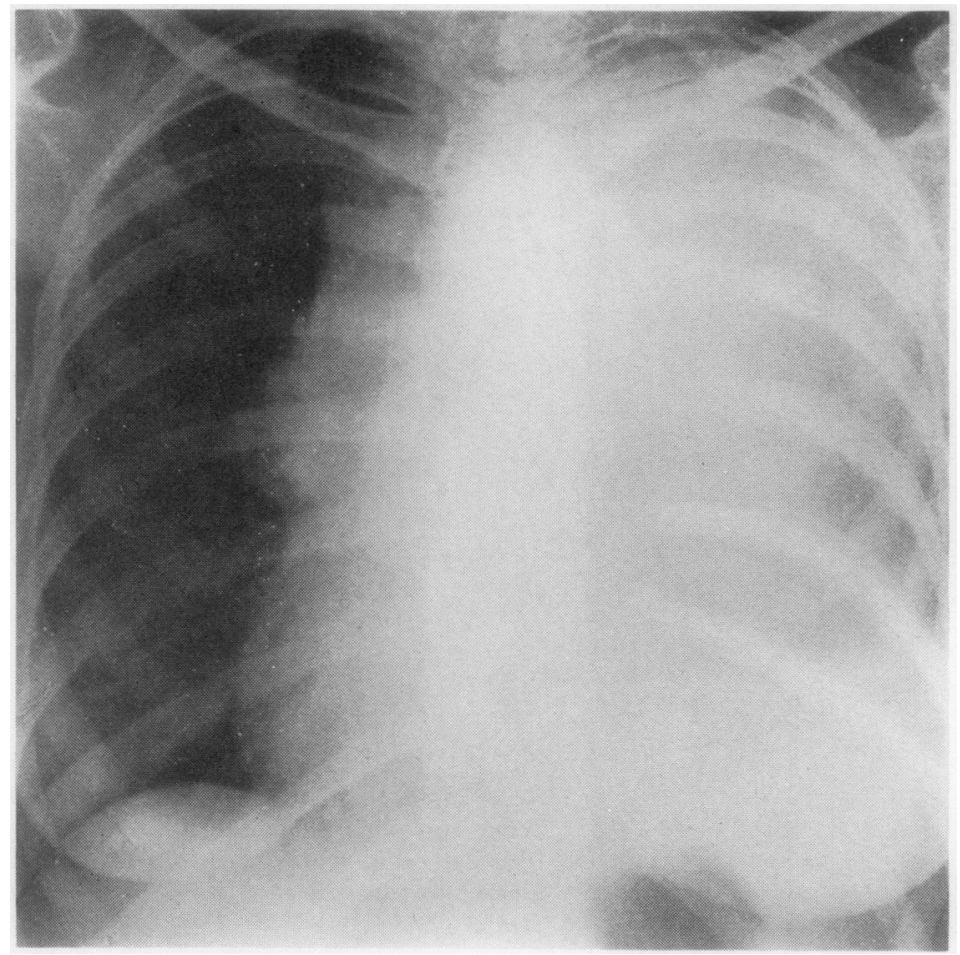

FIG. 5. A 26-year-old woman with epigastric pain, dry cough, fever, and weight loss of two months' duration. A fibrosarcoma was removed through a left thoracotomy.

FIG. 6. Lipoma of pericardium in a 20year-old man with exertional dyspnoea of five years' duration. Total removal of the tumour was accomplished through a right-sided thoracotomy.

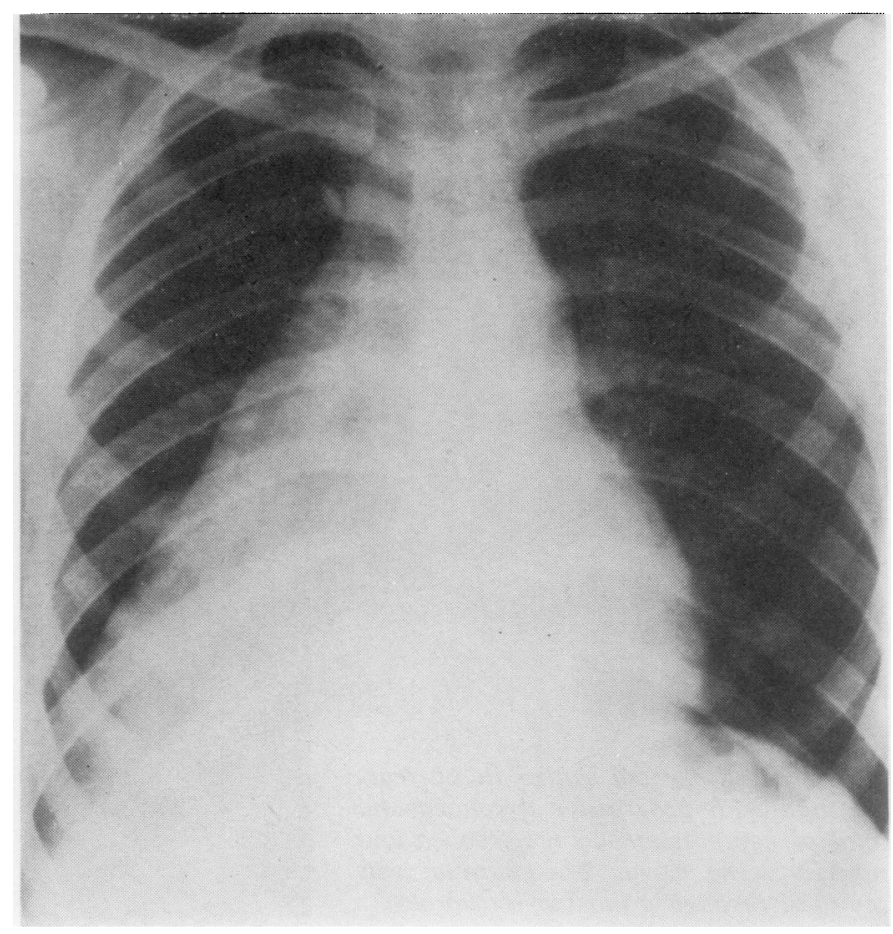




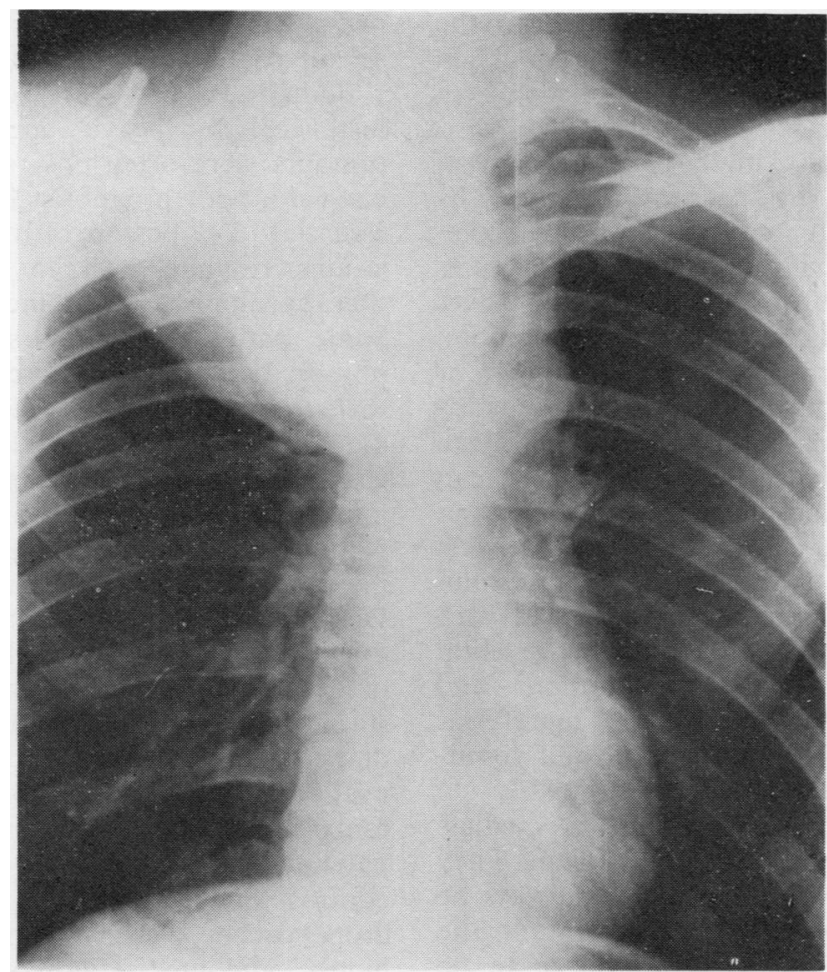

FIG. 7. A 35-year-old man with progressive dyspnoea. A dense opacity is seen in the superior mediastinum with compression of the trachea. A bony tumour was removed piecemeal and reported as an osteoma.

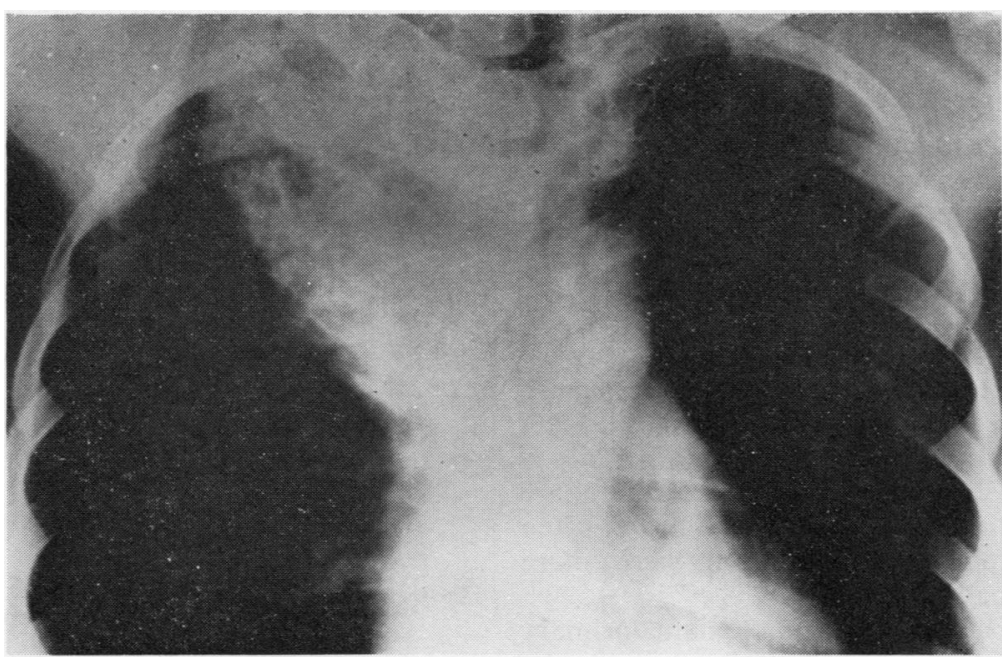

FIG. 8. Chondrosarcoma in a 38-year-old man with pain in the right upper chest of four months' duration. The tumour was removed totally through a right thoracotomy. 
All lymphatic tumours appeared limited to the mediastinum and were found most commonly in the anterior mediastinum. A higher incidence in children was noted.

The thymoma is a potentially highly malignant tumour best treated by excision followed by irradiation therapy. It may cause acute compression on the trachea and threatens life unless decompression is instituted immediately. There are no morphological criteria before operation by which thymoma can be diagnosed as benign or malignant. The immediate criteria of malignancy in thymomas include invasion of the capsule and extension into the adjacent tissues. Invasion can be confirmed only at the time of operation.

Neurogenic tumours were the commonest benign neoplasms of the posterior mediastinum. Usually they involve the intercostal nerves with occasional extension into the intervertebral foramen. Rapid growth of the tumour and necrosis, especially in children with manifestation of common cold, fever, malaise, and vomiting, was reported in one series (Parish, 1971).

Intrathoracic goitres, although often mediastinal lesions, are rarely a thoracic problem. They arise in the neck and they can almost always be removed without entering the chest. Among the cases presented, one case was too large to be removed from the neck (Fig. 4). Radioactive iodine studies are an important adjunct in the diagnosis of retrosternal goitre.

Mesenchymal tumours, although rare, do exhibit diagnostic problems (Figs 5 and 6). Benign and malignant lesions of bone (Fig. 7) and cartilage (Fig. 8) may encroach upon the mediastinum as primary neoplasms and produce compression on the trachea or the superior vena cava and call for emergency decompression. One case of dermoid cyst is presented among the group and was located posteriorly. Two cases of tuberculous lymph node masses were encountered and required surgical exploration for definite diagnosis.

Symptoms varied from general weakness and chest pain to dry cough and exertional dyspnoea.

Most lesions in adults did not produce significant symptoms, whereas most children had symptoms (Whittaker and Lynn, 1973). This is because the majority of lesions in children are malignant. Malignant lesions were more often symptomatic, and benign tumours were more frequent than malignant.

Survival in patients with malignant primary mediastinal neoplasms varied markedly with the frequency of metastasis, the degree of local extension noted at the time of surgery, the nature and degree of cellular differentiation, and $\ddot{\Rightarrow}$ sensitivity to irradiation therapy.

Benign lesions were excised in almost all instances and gave good results. Malignant tumours were often only partially resectable and carried a poor prognosis. Histological diagnosis is essential for postoperative treatment as some is lesions respond well to high-voltage radiation therapy alone or combined with chemotherapy. Some patients may be spared thoracotomy if proper tissue diagnosis can be obtained from scalene or mediastinal node biopsy. However, diagnosis of mediastinal lesions solely by radiography is a most challenging problem. Radiological findings are of primary importance. The routine chest film may suggest mediastinal widening or a mass which calls for further study. Despite the availability of simple and sophisticated diagnostic methods, as well as surgical procedures of lesser magnitude than classical median sternotomy or thoracotomy, specific tissue diagnosis is not always obtained. Some of the available diagnostic methods have made thoracotomy unnecessary, particularly in the poor-risk patient. Radiographs with or without the use of contrast media, sputum studies, skin tests, bronchoscopy, needle biopsy, scalene fat pad biopsy, and mediastinoscopy are frequently employed procedures. Specific clinical and radiological signs, such as vocal cord paralysis, phrenic nerve involvement, extension to adjacent bony structures, compression of the superior vena cava or trachea are late manifestations. However, exploratory thoracotomy or median sternotomy for confirmation of diagnosis and excision of the tumour whenever possible to avoid compression in malignant lesions or malignant changes in benign lesions is advised in all patients who are considered acceptable risks (Alexander, 1942; le Roux, 1962; Boyd and Midell, 1968).

\section{REFERENCES}

Al-Naaman, Y. D., Samarrai, A. A., Al-Khaddar, M. A., and Hasso, L. N. (1972). Are thymic tumours and thymic hyperplasia present as $\omega$ surgical emergencies? Journal of The Faculty $\underset{<}{\sigma}$ of Medicine, Baghdad, 14, 190.

Alexander, J. (1942). Circumscribed intrathoracic neoplasms. Journal of American Medical Association, 119, 395.

Benjamin, S. P., McCormack, L. J., Effler, D. B., and Groves, L. K. (1972). Primary tumors of the mediastinum. Chest, 62, 297.

Boyd, D. P. and Midell, A. I. (1968). Mediastinal cysts and tumors. Surgical Clinics of North America, 48, 493. 
Hallgrimsson, J. G. (1972). Primary mediastinal tumours in Iceland, 1956-70. Thorax, 27, 468.

La Franchi, S. and Fonkalsrud, E. W. (1973). Surgical management of lymphatic tumors of the mediastinum in children. Journal of Thoracic and Cardiovascular Surgery, 65, 8.

le Roux, B. T. (1962). Cysts and tumors of the mediastinum. Surgery, Gynecology and Obstetrics, 115, 695.

Parish, C. (1971). Complications of mediastinal neural tumours. Thorax, 26, 392.
Wychulis, A. R., Payne, W. S., Clagett, O. T., and Woolner, L. B. (1971). Surgical treatment of mediastinal tumors. A 40-year experience. Journal of Thoracic and Cardiovascular Surgery, 62, 379.

Whittaker, L. D. and Lynn, H. B. (1973). Mediastinal tumors and cysts in the pediatric patient. Surgical Clinics of North America, 53, 893.

Requests for reprints to: Professor Yousif D. Al-Naaman, College of Medicine, University of Baghdad, Baghdad, Iraq. 